\title{
GOLPE DE VISTA \\ CINEMA E DITADURA \\ MILITAR NA AMÉRICA DO SUL
}

\author{
RESEÑA
}

Por

Jorge Prudencio Lozano ${ }^{1}$

Universidad del Quindío

jplozano@uniquindio.edu.co

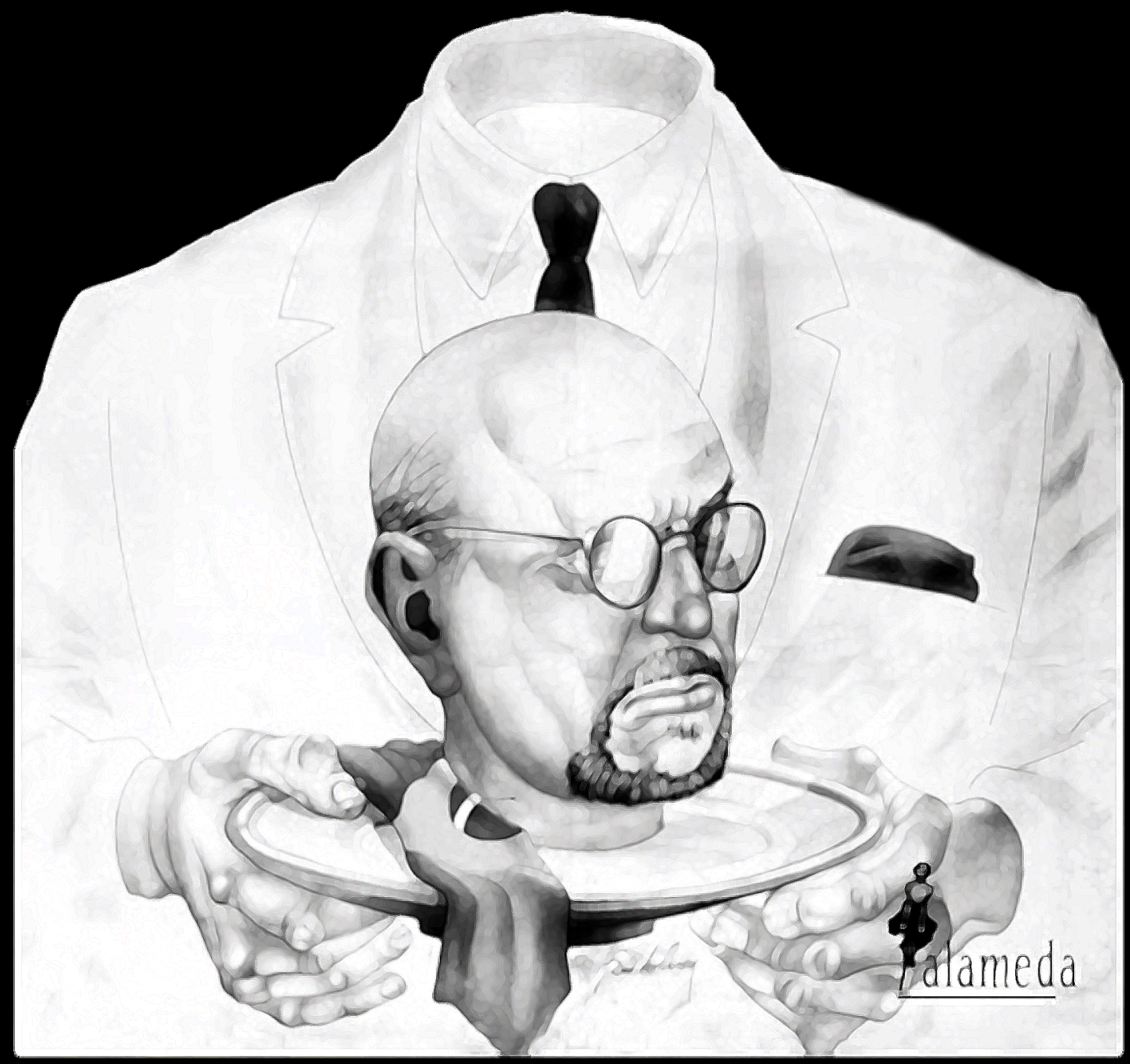

6) Nexus Comunicación • N²3 • Enero - junio de 2018 


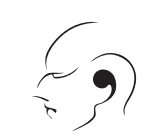

Editorial ALAMEDA, de Sao Paulo, ha publicado en el otoño brasileño de 2018 y en 440 páginas llenas de vida, una colección de 20 artículos sobre el cine y las dictaduras de siete países suramericanos. El título GOLPE DEVISTA, es un juego verbal que, con el primer término, sugiere aquel procedimiento empleado por quienes acceden al poder estatal de manera violenta y, con el último, acaba de incitar figuradamente al lector, especialmente al lector joven, para que obtenga una impresión reveladora, no sólo de la dolorosa historia de las dictaduras, que el tiempo y los medios de comunicación aliados al status quo insisten en frivolizar, distorsionar o incluso borrar, sino también -y sobre todo- de la presencia del cine como testigo, reflexión y protagonista de la lucha y la resistencia contra aquellos nefastos "gobiernos de difuntos y flores".

El libro está escrito en dos secciones. La primera, el Dossier I, está integrado por el aporte de nueve autores que realizan algunas aproximaciones panorámicas al asunto anunciado por el subtítulo: El cine y la dictadura en América del sur. El Dossier II articula 11 textos que profundizan en casos particulares de ese mismo asunto. Así pues, este es un libro reivindicativo de buena parte de la cultura cinematográfica en Suramérica como quiera que ésta sea; y al mismo tiempo, es un documento sobre una parte de la teoría cinematográfica producida en Suramérica, sobre algunos aspectos de la historia del cine suramericano y sobre un cierto cine histórico producido en este subcontinente.

GOLPE DE VISTA parece haber llegado más allá de lo que se propusieron los compiladores: Nuno César Abreu -a cuya memoria está dedicado-, Alfredo Luiz Suppia y Marcius Freire, profesores del departamento de cinema de la Universidad Estatal de Campinas. En efecto, según se menciona en la presentación, inicialmente sólo se quería rememorar el aniversario 25 de la obra cinematográfica Corpo em delito, dirigida por el primero de ellos en 1989. En 2014 resultaba muy importante este gesto para contarle a los jóvenes que los oasis del presente tenían un pasado de sufrimiento... no para atormentar a los jóvenes pero sí para que los oasis fueran mejor entendidos.

Según nos cuentan Suppia y Freire, la iniciativa de Nuno César consistía en publicar el guion y algunas entrevistas con Nelson Pereira, maestro emblemático de aquella época; sin embargo, al profesor Abreu se le acabaron los días y sus conversaciones con Nelson quedaron truncas.

Vale la pena decir que En Corpo em delito, un médico legista al servicio de la dictadura militar que se instauró en Brasil en 1964, se encontró abocado, de repente, a realizar la autopsia de una joven que murió luchando contra la dictadura y que resultó ser su 
propia hija. De tono intensamente dramático por su factura, tal como lo señalan los organizadores del libro, esta obra cinematográfica puede ser considerada el canto del cisne de EMBRAFILM, la empresa productora estatal que feneció con la entrada del neoliberalismo a este país.

Se entiende que en el libro no haya alusiones directas a las cinematografías venezolana y colombiana, países en los que las élites se han vanagloriado de no haber vivido dictaduras (por lo menos de mando militar). Tampoco alcanzaron a entrar en el libro alusiones directas al cine boliviano y particularmente a la producción cinematográfica y teórica de Jorge Sanjinés, esta última sintetizada en Por un cine junto al pueblo (quizás por razones prácticas relacionadas con las circunstancias en que se desenvuelve el intercambio cultural entre Brasil y Bolivia). Aun así, en los aspectos teóricos el libro le presta atención a otras dos de las reflexiones más importantes que se han producido en Suramérica: El tercer cine, de Solanas y Getino y La estética del hambre, de Glauber Rocha.

Sobre el tercer cine, Mariano Mestman, además de precisarlo conceptualmente en cuanto a que debía producirse para aportar a la liberación nacional (a diferencia del cine de Hollywood o primer cine y del cine de autor o segundo cine), ofrece una perspectiva poco conocida: la de los exhibidores del cine militante (el subtipo más importante dentro del tercer cine) que se jugaron la vida a finales de los sesenta y comienzos de los setenta, llevando clandestinamente ilusiones a los pobladores de los sectores marginados en Argentina. Sin embargo no fue mero activismo, sino una reflexión teórica sobre la cultura cinematográfica a partir de consideraciones -también teóricas- acerca de la cultura en general y sobre la práctica política en particular.

Por su parte, Ignacio Del Valle le da relieve a las tensiones y conciliaciones, a veces explícitas y a veces implícitas, entre el tercer cine y la estética del hambre. Nos señala Del Valle que, de partida, el tercer cine reprochó a la obra de Glauber al incluirla dentro del "individualismo de autor", pero el brasileño enfatizó en la necesidad de ser creativo en los aspectos formales y recalcó que un auténtico autor es el que se compromete con la transformación política de la sociedad a la que denuncia. Con ese presupuesto, Solanas reconoció en el cinema Novo a una posibilidad del tercer cine.

Las anteriores reflexiones resultan muy pertinentes para nuestra época si se considera que el estructuralismo y la hermenéutica (de origen europeo) parten del análisis del texto, mientras que el tercer cine y la estética del hambre lo hacen desde el contexto. Esto último no es apenas una postura situada en la Suramérica de las décadas de los sesenta y setenta, sino que hoy se relaciona con las identidades que buscan reivindicarse y emanciparse en diferentes lugares del planeta, mucho más 
si se consideran las apariencias que toman el neoliberalismo y la ignominia. Tanto productores como estudiosos requieren del diálogo y la conjugación del texto y el contexto.

Los demás aportes que conforman a esta primera parte del libro -aún sin hacer alusiones explícitas a estas posturas teóricas- las evocan al mencionar obras cinematográficas que bien podrían ser adoptadas por los postulados del tercer cine o el cine comprometido; o en cualquier caso, son obras que parten del contexto para llegar a las búsquedas formales, es decir, a la creatividad en el texto.

Así ocurre, por ejemplo, con los acercamientos de Javier Campo a la resistencia en el exilio: el documental político argentino entre 1976 y 1984 o El dragón del gorilismo contra la memoria guerrera: las cinematecas latinoamericanas en tiempos de dictadura, de Fabian Nuñez.

De esta manera también se construye una postura frente a lo que en términos teóricos y prácticos se puede entender como cine histórico. Los hechos son asumidos desde un punto de vista definido, en este caso ya no desde los vencedores que institucionalizan a una historia oficial sino desde los vencidos y marginados o, si se prefiere, desde los que luchan, desde los oprimidos y los exiliados. Este es el tono que resuena en La pantalla presa en Libertad, de Cecilia Lacruz, sobre el rol de la resistencia por medio del cine en Uruguay entre 1972 y 1985. Luis Dufuur continúa en esa dirección en Anotaciones sobre los filmes desarrollados en el proceso cívico militar uruguayo (1973-1984) y lo confirma Mariana Villaca en Del combate directo al mensaje cifrado: notas sobre el cine uruguayo entre 1967 y 1985.

Ya en la segunda parte, si bien Marcius Freire dedica su atención específicamente a dos obras de Chris Marker -como parte de la serie Estamos hablando de Brasildebido al particular estilo del cineasta francés, también refuerza una concepción de cine histórico en la que menos que pretender reconstruir unos hechos, lo que interesa es la reconstitución de una atmósfera y una época. Lo propio hace Francisco Elinaldo Texeira al ahondar en la fuerza alegórica de dos obras producidas con 11 años de diferencia: Mató a la familia y fue al cine (Bressane,1969) y La edad de la Tierra, (Rocha, 1980).

Igualmente se detecta una apertura hacia un cine histórico de la resistencia política en El pasado, hoy: la dictadura militar en tres filmes brasileros de tiempos entrelazados, de Carolina Gomes Leme y en la indagación de Carolina Amaral de Aguiar sobre El cine latinoamericano y la solidaridad con Chile, haciendo referencia al cine hecho fuera del país austral pero en solidaridad con quienes combatían a la dictadura de Pinochet.

Otra cosa es la Historia del cine, dedicada a dar cuenta de marcas significativas dentro de la trayectoria de producción de una cinematografía en particular. Esto es lo que hace Carlos Reyna en el último aporte de la primera parte al escribir un texto 
panorámico sobre el Cine y dictadura en el Perú: actores sociales y personajes políticos. Mientras tanto, Priscila Bettim se focaliza en tres filmes del director Andrea Tonacci con el trasfondo de la dictadura brasileña.

De todas maneras, manteniendo una postura crítica frente a la Historia, se presenta el texto Los significados del desplome en el filme "La caída", de Ruy Guerra y Nelson Xavier; con habilidad reflexiva María Leandra Brizello escribió Acción entre amigos; la memoria posible; y Marina Soler Jorge analizó la censura en una serie comercial: Magnífica 70. Por su parte, Alfredo Suppia y Roberto Causo en Tan bueno que era mi robot. Cine brasileño de ciencia ficción, guerra fría y dictadura militar, exploran y señalan los significados políticos profundos de este género que comúnmente es asumido como mero entretenimiento; a su vez, Denise Tavares analiza a las dictaduras en Ecuador y Paraguay a través de dos filmes: Con mi corazón en Yambo (Restrepo, 2011) y Cuchillo de palo, 108 (colectivo mansión 108, 2010), respectivamente.

El libro incluye también un artículo de José Ignacio de Melo Souza sobre la obra Hambre de amor, de Nelson Pereira, a quien, como ya se dijo, Nuno César Abreu aspiraba a entrevistar. Sin embargo, Nuno se fue antes de materializar este libro y Pereira casualmente murió cuando ya estaba en la imprenta.

Este es un libro dedicado a la memoria: a la de su inspirador, a la de quien iba a ser su personaje central y a la de tantas víctimas de las dictaduras. Todos los autores son de reconocida trayectoria académica y la presentación en solapa estuvo a cargo de Jorge Nóvoa, profesor titular de Ciencias Sociales en la Universidad Federal de Bahía. Aunque en el Dosier I hay seis aportes escritos en español, el resto de textos están escritos en portugués con la grafía actualizada según el acuerdo ortográfico de lengua portuguesa de 1990, que entró en vigor en Brasil en 2009. La carátula es semidura y está ilustrada con un layout de Carlos Fernández sobre la ilustración que hizo Raul de Oliveira para el afiche del filme Corpo em delito (Abreu, 1989).

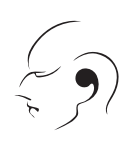


${ }^{1}$ Jorge Prudencio Lozano Botache es profesor de la Universidad del Quindío. Cineasta con especialidad en Guion Cinematográfico, Comunicador social con énfasis en comunicación comunitaria, Especialista en Filosofía con énfasis en epistemología y ética, Doctor en Ciencias de la Educación con énfasis en didáctica, pedagogía y currículo, con una tesis sobre cine y ducación. Posdoctorado en cine. Autor de varios artículos sobre cine, educación y TIC, publicados en Colombia, México, Perú y España. Autor del libro "La Historia de Colombia en el cine de ficción hecho en Colombia". Coautor del libro "Representaciones Audiovisuales". Autor del libro "Narración cinematográfica: potencialidades pedagógicas y de investigación cualitativa”. Autor de varias obras audiovisuales de carácter cultural y educativo. Profesor de la Universidad del Quindío. Líder del grupo de Investigación CINEDADES: Narración y Sociedad (Universidad del Quindío, Colombia).

Recibido: 04 de mayo de 2018 / Aprobado: 20 de junio de 2018

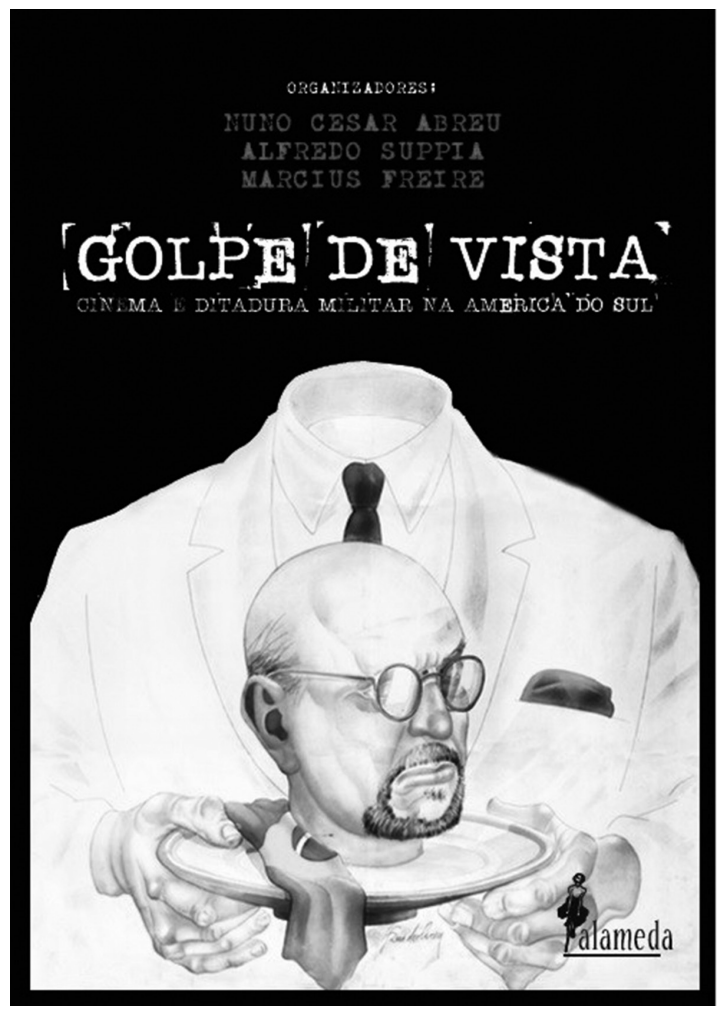

